\title{
Induction of Lateral Root Structure Formation on Petunia Roots: A Novel Effect of GMI1000 Ralstonia solanacearum Infection Impaired in Hrp Mutants
}

\author{
Lena Zolobowska, ${ }^{1}$ and Frédérique Van Gijsegem ${ }^{2}$ \\ ${ }^{1}$ Department of Plant Systems Biology, Flanders Interuniversity Institute for Biotechnology, Ghent University, \\ Technologiepark 927, B-9052 Ghent, Belgium; '2Laboratoire Associé de l'Institut National de la Recherche Agronomique \\ (France), Ghent University, B-9000 Ghent, Belgium
}

Submitted 15 July 2005. Accepted 28 January 2006.

\begin{abstract}
Ralstonia solanacearum is a soilborne plant pathogen that invades its host via roots. As in many gram-negative bacterial plant pathogens, the $R$. solanacearum Hrp type III secretion system is essential for interactions of the bacterium with plants; however, the related mechanisms involved in disease expression are largely unknown. In this work, we examined the effects of infection by $R$. solanacearum GMI1000 and Hrp mutants on the root system of petunia plants. Both the wild-type and mutant strains disturbed the petunia root architecture development by inhibiting lateral root elongation and provoking swelling of the root tips. In addition, GMI100 but not the Hrp mutants induced the formation of new root lateral structures (RLS). This ability is shared by other, but not all, $R$. solanacearum strains tested. Like lateral roots, these new structures arise from divisions of pericycle founder cells which, nevertheless, exhibit an abnormal morphology. These RLS are efficient colonization sites allowing extensive bacterial multiplication. However, they are not required for the bacterial vascular invasion that leads to the systemic spread of the bacterium through the whole plant, indicating that, instead, they might play a role in the rhizosphere-related stages of the $R$. solanacearum life cycle.
\end{abstract}

Additional keywords: bacterial wilt.

To interact with their hosts, pathogenic bacteria produce a battery of virulence factors that allow entry of the bacteria into their host, followed by bacterial invasion and multiplication, ultimately leading to disease symptom expression and transmission to other hosts. Systems devoted to the secretion of proteins play a predominant role in the cross-talk arising during the interaction of pathogens with their hosts. In this cross-talk, the seminal importance of type III secretion systems (TTSSs), shared by many gram-negative bacterial pathogens of mammals

Corresponding author: F Van Gijsegem; Telephone: 33-1-44087259; Fax: 33-1-44081631; E-mail: vangijse @ inapg.fr

Current address of L. Zolobowska: Laboratoire de Nutrition Azotée des Plantes, INRA, Route de Saint Cyr, 78026 Versailles, France.

Current address of F. Van Gijsegem: Laboratoire Interactions Plantes Pathogènes, UMR217 INRA/INA P-G/UPMC, 16 rue Claude Bernard F75231 Paris Cedex05, France. and plants, is now well documented, and several effector proteins trafficking through these systems have been identified (Cornelis and Van Gijsegem 2000; Mudgett 2005). Furthermore, the use of bioinformatic methods is facilitating the discovery of more putative novel effectors (Collmer et al. 2002; Cunac et al. 2004).

In mammalian pathogens, the function of several type III effectors has been elucidated; they were shown to interfere with host cytoskeletal pathways, host defence systems, and signalling cascades to facilitate bacterial survival and replication and promote disease (Cornelis and Van Gijsegem 2000). In plant pathogens, TTSS effectors often were characterized as the products of avirulence (avr) genes. Avr proteins are host specificity factors that trigger specific defence responses in plants harboring the corresponding resistance gene (Leach and White 1996; Mudgett 2005). These defence responses often are associated with the induction of the hypersensitive response (HR), a local programmed cell death of plant cells surrounding the site of infection. The signalling pathways leading to resistance have been studied extensively (Rathjen and Moffett 2003); however, the deciphering of the plant pathways important for disease onset is largely in its infancy. Some $a v r$ genes were shown to be involved in bacterial fitness during their interactions with plants; however the underlying mechanisms are unknown (Leach and White 1996; Mudgett 2005). Xanthomonas type III effectors of the AvrBs3 family were shown to induce cell divisions and cell enlargement in plant leaves. Additionally, expression of the AvrBs3 protein in planta can modulate the expression of host plant genes that may be involved in the hypertrophy phenotype associated with disease symptoms (Duan et al. 1999; Marois et al. 2002; Yang et al. 1994). A recent advance also came from the demonstration that effector proteins injected by bacterial TTSSs into the eukaryotic host cell act as suppressors of plant general resistance (Abramovitch et al. 2003; Abramovitch and Martin 2004; Hauck et al. 2003; Keshavarzi et al. 2004; Mackey et al. 2003).

The phytopathogenic gram-negative bacterium Ralstonia solanacearum causes bacterial wilt disease in several plant species, including economically important crops such as potato and tomato. The bacterium is distributed worldwide in tropical, subtropical, and some warm temperate regions. It is a soilborne pathogen well adapted to life in the soil. It infects plants via roots where the bacteria reach the vascular system and, subsequently, spread systemically throughout the plant (Hayward 1991). The $R$. solanacearum TTSS Hrp system is essential for 
disease development (Arlat et al. 1992). Analysis of the recently determined genome sequence revealed more than 40 putative type III effectors (Cunac et al. 2004; Salanoubat et al. 2002). Five of these effectors have been characterized (Arlat et al. 1994; Deslandes et al. 2003; Guéneron et al. 2000; Lavie et al. 2002). Some, like PopP1 and PopP2, behave like avirulence genes. The PopA protein is a member of the plant pathogen type III effector proteins called harpins that, when purified, are able to induce HR-like defence responses after infiltration into plant leaves (Arlat et al. 1994; Cornelis and Van Gijsegem 2000). Interestingly, in the host plant petunia, only certain genotypes are reactive to PopA and this reactivity was found to be associated to resistance to bacterial wilt (Arlat et al. 1994). However, the role in disease expression for these five effectors remains elusive.

While analyzing the effects of $R$. solanacearum GMI1000 infection on petunia roots, we discovered that this bacterium promotes the induction of new root structures and that Hrp mutants lost this capacity. These structures are highly efficient colonization sites, allowing extensive bacterial multiplication. However, they are not required for the bacterial vascular invasion that leads to the systemic spread of the bacterium through the whole plant, instead indicating a role in the rhizosphererelated stages of the $R$. solanacearum life cycle.

\section{RESULTS}

\section{R. solanacearum infection interferes with petunia root development.}

$R$. solanacearum is a soil pathogen that invades its hosts via roots. To analyze the early events following bacterial infection, roots of $\mathrm{Skr} 4$ petunia plantlets grown in vitro on vertical agar plates were infected by flooding the root system with an $R$. solanacearum GMI1000 bacterial suspension, and the effects of bacterial infection on root development were examined (Fig. 1). Compared with water-treated control plantlets (Fig. 1B), bacterial infection caused several perturbations of root development, such as swelling of root tips, reduced elongation of the main and lateral roots, and inhibition of lateral root development. In addition, many small, evenly spaced bulges appeared on the main root and elongated lateral roots of infected plantlets (Fig. 1C and G). These effects of bacterial infection were analyzed quantitatively 7 days after infection by scoring the extent of main root elongation and by counting the number of developed lateral roots and of small, emerging bulges that became visible in the region between the root tip and the latest developed lateral root at the time of inoculation (Table 1). After bacterial infection, the main root elongation was only $12 \%$ of that observed in control plantlets, and an increase of more than 10 -fold was observed in the production of emerging bulges.

\section{The formation \\ of emerging bulges requires a functional Hrp TTSS.}

To check the effect of Hrp mutations on the alterations of petunia root development induced by $R$. solanacearum infection, we analyzed the interactions of the petunia root system with an $h r c R$ mutant, altered in one constituent of the type III secretion apparatus, or an $h r p B$ regulatory mutant (Fig. 1; Table 1). Both hrp mutants still were able to inhibit the elongation of the main root. This inhibition was slightly less for the $h r p B$ mutant compared with the effects of wild-type inoculation. In contrast, the number of developed lateral roots was only slightly decreased after inoculation with both hrp mutants and the formation of small bulges was not induced (Fig. 1D, E, H, and I). This indicated that the induction of bulge formation was not related to the inhibition of the main root tip elongation. In the rest of this article, these bulges will be referred to as root lateral structures (RLS). To rule out the fact that this effect might be due to plant growth on agar plates, we also checked if RLS formation could be induced in soil-grown plantlets. Potted plants were inoculated by watering with a $10^{8}$ bacteria/ml suspension of either a wild-type strain or Hrp mutants, as described in Material and Methods. After infection with wild-type bacteria, bulges were observed on the root system of soil-grown plants, though this induction was not observed as regularly as after flooding of agar-grown plantlets (Fig. 1J). No such bulges were observed with Hrp mutants.

The Skr4 petunia line was shown to be resistant to $R$. solanacearum (Arlat et al. 1994). To check whether the formation of the RLS might be correlated to resistance, we analyzed the effect of $R$. solanacearum infection on the root system of the susceptible Tr66 petunia line. The Skr4 and Tr66 root systems are very different (Figs. 1A and 2A). The Tr66 root system was much more branched, accumulating several lateral roots. Nevertheless, both the inhibition of main root elongation and the formation of RLS could be observed (Fig. 2; Table 1), indicating that these phenomena were not linked to resistance or susceptibility to bacterial wilt.

We also examined how the ability of inducing RLS was distributed in different $R$. solanacearum strains. Four strains were analyzed: two of them (GA3 and GMI8084) provoked the same alterations of the petunia root system, including RLS induction, as those observed after GMI1000 inoculation. The K60 strain induced root tip swellings and main root growth inhibition, but no RLS were detected. Inoculation with the AW1 strain had no apparent effect on root architecture (data not shown).

\section{Kinetics of the formation of RLS during infection.}

The RLS began to emerge as small protrusions as early as 3 days after infection. They expanded with time but never developed into elongated lateral roots. To check whether the formation of these structures was continuously induced during bacterial infection, a light microscopy analysis of infected roots was performed 3, 5, and 7 days after bacterial inoculation. The RLS were counted at the different timepoints and divided into two categories according to their size: nascent bulges that just protruded out of the parent root surface or mature RLS that formed a clearly visible dome on the root surface. Although the total number of RLS progressively increased with time, the number of nascent structures was comparable at all three timepoints (Fig. 3). This indicated that new RLS were formed continuously during the infection and that these structures continued to develop with time.

\section{Morphology of the RLS.}

To obtain a more precise insight into the nature of the RLS and their relation to normal lateral roots, a microscopic analysis of resin-embedded petunia roots was performed (Fig 4). For a comparison, the developmental stages of Skr4 normal lateral roots from untreated plants are presented in Figure 4A to C. As previously described for other plants (Charlton 1996; Malamy and Benfey 1997; Peterson and Peterson 1986), the first stages of lateral root primordium formation in petunia took place in the pericycle layer of the root adjacent to xylem poles. The cells at the sites of primordium initiation arose from regular anticlinal and periclinal divisions, leading to the formation of two symmetrical cell layers (Fig. 4A, asterisk). At these sites of pericycle divisions, cell divisions in the adjacent endodermal layer also were observed (Fig. 4B, arrow). When they emerged through the main root surface, the new lateral roots exhibited well-organized layers of regular cells, an apical meristem, and newly formed xylem vessels, also called connector xylem (Fig. 4C). In R. solanacearum-inoculated roots, numer- 
ous cell divisions also occurred in the pericycle at the xylem poles of the main root. However, they followed an aberrant developmental pattern leading to the formation of small, irregular cells arising from aberrantly oriented planes of divisions (Fig. 4D, asterisk). At these sites of abnormal divisions, unorganized groups of large cells also could be observed (Fig. 4E, star). Larger RLS often consisted of a disorganized mass of large, round cells. Most of the bacteria-induced RLS possessed connector xylem-like tissues; however, no small meristematic cells were ever observed (Fig. 4F). The morphology of the RLS induced by $R$. solanacearum on the roots of the Tr66 line showed similar aberrant developmental characteristics (Fig 4G to I). Infected roots of both lines also developed RLS that exhib- ited an intermediate morphology, with the base consisting of rather well-organized cell layers, including xylem vessels, but the apex being composed of large, round cells (Fig. 4J). Normally developing lateral root primordia and emerging lateral roots never were observed on infected plants. On the contrary, all the emerging structures present on uninoculated roots exhibited the morphology of normal emerging lateral roots, showing that the formation of RLS is restricted to inoculated plants.

\section{The RLS are efficient colonization sites.}

Plant-bacteria parasitic interactions may take place at different levels. Bacteria either may colonize the plant's external surface, invade the plant's internal tissues, or spread systemi-
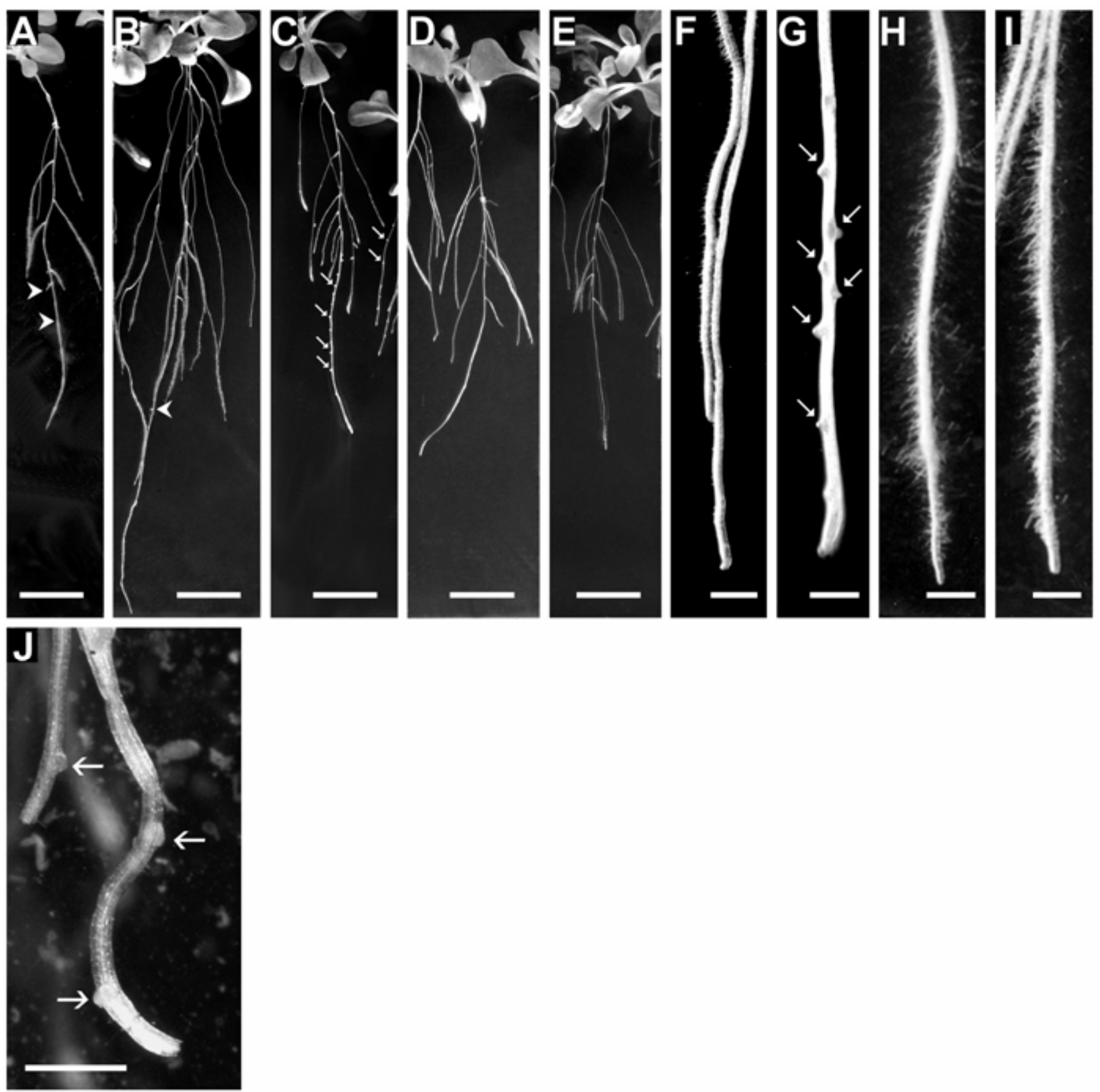

Fig. 1. Morphological changes induced by Ralstonia solanacearum infection on Skr4 petunia roots. A, Root system at the time of inoculation. B, Root system of a plant treated with water $\mathbf{C}$ to $\mathbf{E}$, Root systems of plants treated with $R$. solanacearum strains as follows: C, GMI1000 wild type, D, $h r c R$ mutant, and $\mathbf{E}, \operatorname{hrpB}$ mutant. F to I, Magnification of the root ends of plants treated with $\mathbf{F}$, water or $R$. solanacearum strains as follows: G, GMI1000 wild type, $\mathbf{H}$, hrcR mutant, and $\mathbf{I}, h r p B$ mutant. Arrows indicate root lateral structures (RLS). Plants were photographed 7 days after inoculation. J, RLS produced on the root system of soil-grown plants. Roots were photographed 2 weeks after inoculation. Bars $=1 \mathrm{~cm}$ (A to E, J), $1 \mathrm{~mm}(\mathrm{~F}$ to I), and $0.5 \mathrm{~mm}(\mathrm{~J})$. 
cally through the whole plant. The importance of the RLS in these different aspects of plant-bacteria interactions was evaluated by analyzing microscopically the localization of bacteria on and in infected petunia roots. To allow the visualization of bacteria in planta, $R$. solanacearum derivatives carrying either a constitutively expressed $g f p$ gene (GMI 1600) or an Escherichia coli lacZ reporter gene (GMI 1485) were used. Examination of the whole, intact root system of plantlets infected with the $g f p$-marked bacteria revealed that, $24 \mathrm{~h}$ after inoculation, bacteria were distributed evenly on the root surface (data not shown). However, starting from the second day postinoculation, the bacteria were preferentially detected at three sites on petunia roots: the subapical regions of main and lateral roots, the axils of developed lateral roots, and the surface or axils of the RLS (Fig. 5A, B, and C). To compare the localization of the bacteria at the axils of lateral roots and at RLS, roots were infected with the lacZ-expressing strain GMI1485, allowing the visualization of the bacteria by X-gal (5-bromo-4chloro-3-indolyl- $\beta$-D-galactoside) staining after fixation of the
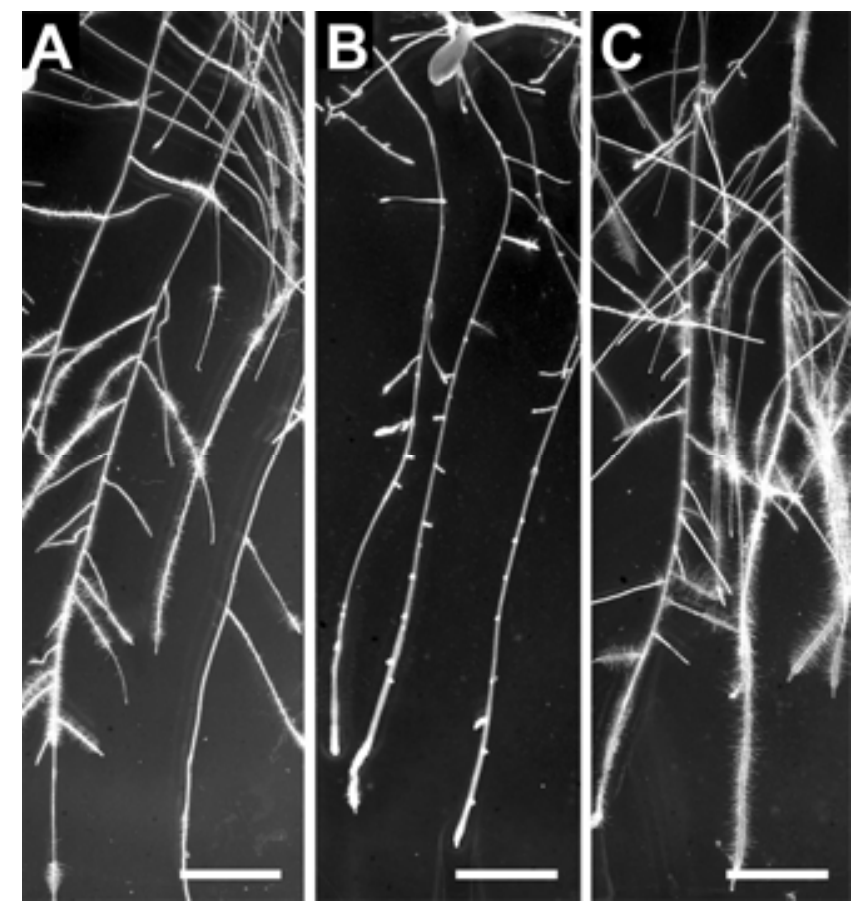

Fig. 2. Effects of Ralstonia solanacearum inoculation on the roots of the susceptible Tr66 petunia line. Plants were treated with A, water, B, $R$. solanacearum GMI1000 wild-type strain, or $\mathbf{C}$, hrpB mutant. The plants were photographed 7 days after inoculation. Bars $=1 \mathrm{~cm}$. plant material and sectioning. Both entire roots and sections were analyzed (Fig 5). The colonization pattern was similar at both sites and mainly was limited to the root surface and the epidermal cell layer, where bacteria-filled epidermal cells of the parent root adjacent to lateral root axils (Fig. 5E) or to the sites of RLS emergence (Fig. 5G and I) could be observed. At RLS, bacteria also could be detected in the cracks in the parent root caused by the emergence process (Fig. 5F and G) and, for heavily colonized ones, on the whole surface (Fig. 5H and M). When these sites were highly colonized, bacteria sometimes even could penetrate into the intercellular spaces of the most external cortex layers (data not shown). Although the colonization pattern appeared to be similar at lateral roots axils and RLS, the intensity of colonization appeared much higher at mature RLS (Fig. 5M). To follow the kinetics of bacterial accumulation, we estimated the number of bacteria present at these sites by scoring the intensity of X-gal staining and the size of the infected area following the scale described in Materials and Methods (Fig. 5J to M). The data presented in Figure 6 indicate that the intensity of colonization at all sites increased with time in both petunia lines, but it was not evenly distributed on RLS. The nascent RLS were less colonized than mature ones at all timepoints after inoculation in both petunia lines. Even 7 days after inoculation, $40 \%$ of the nascent RLS showed no signs of colonization, although more than $95 \%$ of the mature ones were at least slightly colonized. In plants inoculated with

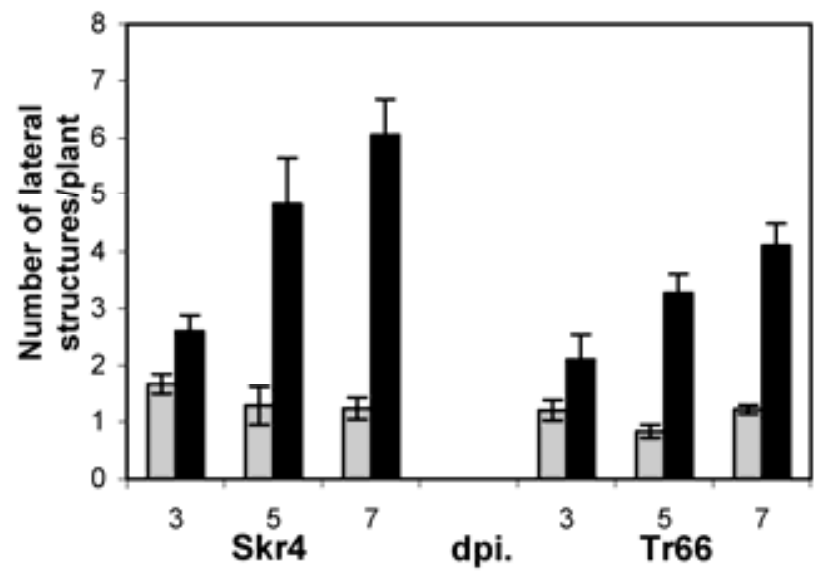

Fig. 3. Kinetics of root lateral structures (RLS) formation during infection. The roots were examined microscopically and the bulges present on the main root were counted 3, 5, and 7 days after inoculation. Gray bar = nascent RLS and black bar = total number of RLS. Error bars indicate standard deviation calculated from three independent experiments in which 20 plants were examined.

Table 1. Effects of Ralstonia solanacearum infection on petunia roots ${ }^{\mathrm{y}}$

\begin{tabular}{|c|c|c|c|}
\hline \multirow[b]{2}{*}{ Petunia line/bacterial strain } & \multicolumn{3}{|c|}{ Average number of } \\
\hline & Developed lateral roots/plant & RLS/plant ${ }^{\mathrm{z}}$ & Elongation of main root $(\mathrm{cm})$ \\
\hline \multicolumn{4}{|l|}{$\overline{\text { Resistant line }}$} \\
\hline $\mathrm{Skr} 4 / \mathrm{H} 2 \mathrm{O}$ & $1.9 \pm 0.5 \mathrm{a}$ & $0.4 \pm 0.4 \mathrm{a}$ & $3.4 \pm 0.1 \mathrm{a}$ \\
\hline Skr4/GMI 1000 & $0.6 \pm 0.6 b$ & $7.6 \pm 1.6 b$ & $0.4 \pm 0.1 \mathrm{c}$ \\
\hline $\mathrm{Skr} 4 / h r c R$ & $1.4 \pm 1.0 \mathrm{a}$ & $0.4 \pm 1.4 \mathrm{a}$ & $0.3 \pm 0.1 \mathrm{c}$ \\
\hline $\mathrm{Skr} 4 / h r p B$ & $1.3 \pm 0.6 \mathrm{a}$ & $0.4 \pm 0.3 \mathrm{a}$ & $0.6 \pm 0.1 \mathrm{~b}$ \\
\hline \multicolumn{4}{|l|}{ Susceptible line } \\
\hline $\operatorname{Tr} 66 / \mathrm{H} 2 \mathrm{O}$ & $4.8 \pm 1.6 \mathrm{a}$ & $0.2 \pm 0.2 \mathrm{a}$ & $2.2 \pm 0.4 \mathrm{a}$ \\
\hline Tr66/GMI 1000 & $0.7 \pm 0.6 b$ & $5.7 \pm 1.0 \mathrm{~b}$ & $0.6 \pm 0.1 \mathrm{c}$ \\
\hline $\operatorname{Tr} 66 / h r c R$ & $4.8 \pm 1.3 \mathrm{a}$ & $0.3 \pm 0.2 \mathrm{a}$ & $0.7 \pm 0.2 \mathrm{c}$ \\
\hline $\operatorname{Tr} 66 / h r p B$ & $2.1 \pm 1.0 \mathrm{~b}$ & $0.1 \pm 0.1 \mathrm{a}$ & $1.2 \pm 0.3 b$ \\
\hline
\end{tabular}

${ }^{y}$ Roots were examined 7 days after inoculation. The structures present in the part of the main root between the root tip and the latest developed lateral root at the time of inoculation were counted. Results were scored as different (a, b, c) when $P<0.05$ using one-way analysis of variance, Tukey's, or Dunnett's multiple comparison tests. These data were derived from three independent experiments including 20 plants each.

${ }^{\mathrm{z}}$ RLS $=$ root lateral structures. 
$g f p$-marked bacteria, such nascent RLS showing no signs of bacteria presence also were commonly found (Fig. 5A, arrowhead; data not shown). This indicates that the absence of bacteria on the surface of RLS in X-gal staining experiments was not due to the washing procedure. These data suggest that intensive bacterial proliferation is not required for the induction of RLS formation and that the lateral structures are formed prior to intensive colonization of their site of emergence.

On the other hand, mature RLS were more colonized than lateral root axils at all three timepoints for both petunia lines and, although the colonization of lateral root axils was comparable in both petunia lines, mature RLS were more intensively colonized in the susceptible Tr66 line.

\section{The RLS are not required for vascular invasion.}

Lateral root emergence causes the parent root surface to break that creates an opening for bacterial infection. In tomato (Vasse et al. 1995), R. solanacearum was shown to penetrate the roots via such openings before reaching vascular vessels and systemically invading the whole plants. To check whether the RLS contributed to vascular invasion in petunia, we compared invasion in roots of plants infected by either the wildtype bacterium or the $h r p B$ mutant that did not induce the formation of lateral structures. First signs of vascular colonization were observed as early as 2 days postinoculation (dpi) (Fig. $5 \mathrm{~N})$. Later, the numbers of bacteria present in the xylem and the portion of vascular vessels colonized increased (Fig. 5O) so that, $7 \mathrm{dpi}$, intense staining of entire vascular bundles (Fig. $5 \mathrm{P}$ ) in large portions of the root system could be observed. Analysis of the vascular colonization kinetics in the Tr66 line showed that such a progression of bacteria into the xylem (Fig. $5 \mathrm{O}$ and $\mathrm{P}$ ) was observed with both the wild-type and the $h r p$ bacteria; and, $7 \mathrm{dpi}, 66$ to $35 \%$ of infected plants, respectively, exhibited vascular colonization (Table 2). Vascular invasion began mostly up to the third day after inoculation (that is, before the formation and intensive colonization of most of the RLS); therefore, the dynamics of vascular invasion appeared to follow a pattern different from the one observed for the development and colonization of RLS.

\section{DISCUSSION}

In this work, we present evidence that $R$. solanacearum disturbs the petunia root architecture development by inhibiting lateral root elongation and inducing the formation of new root lateral structures that provide new sites for extensive bacterial colonization. This appears to be a global effect involving the whole root system. Some of these alterations were induced after inoculation by both the wild-type bacterium and Hrp mutants; nevertheless, the induction of the new root lateral structures required a functional Hrp system.

\section{The RLS are related}

\section{to lateral root primordia but are abnormal.}

Like normal petunia lateral roots, the RLS are evenly distributed along the parent roots and originate from the division of pericycle cells. This may indicate that sites having the capacity of forming new lateral roots are recruited for the formation of the RLS. However, the cells forming the RLS are abnormal; they arise from erratically oriented planes of divisions of pericycle cells and are not organized in regular cell layers. Lateral root development is a two-stage process. First, a lateral root primordium derived from dividing pericycle founder cells is formed. A subset of these primordium cells continues to enlarge, forming a bulge that protrudes out of the parental root epidermis. This first step is followed by the establishment and activation of an organized meristem. Different genetic controls of these two steps were highlighted in Arabidopsis by the characterization of mutants altered in these stages (Casson and Lindsey 2003). In RLS formation, only the first step appears to be activated because we never detected meristems. However, the observation of traces of vascular system suggests that some differentiation occurs. This might be related to the fact that, in
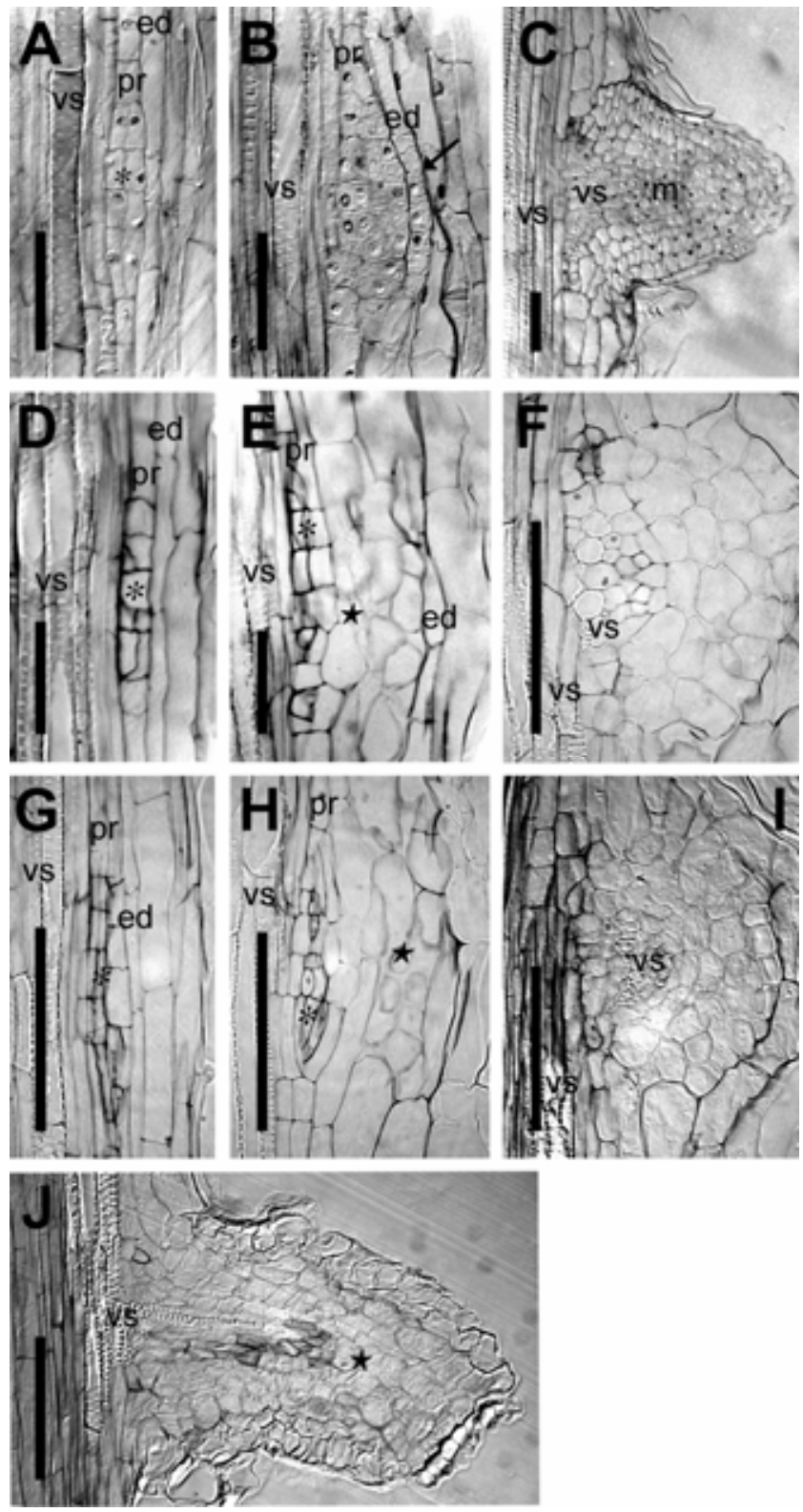

Fig. 4. Morphology of the new root lateral structures (RLS). The plant material was harvested 7 days after inoculation, embedded in Technovit, stained with ruthenium red, and analyzed using differential interference contrast microscopy. A, B, and C, Root sections of control plants (Skr4 line) treated with water showing the developmental stages of petunia lateral root formation. A, Cell divisions in the pericycle layer and formation of two distinct layers of regularly arranged daughter cells (asterisk). B, More developed lateral root primordium showing the regular cell pattern of the dividing cells and divisions in the endodermis layer (arrow). C, Small lateral root breaking through the parent root surface with vascular vessels and meristem. D to J, Sections through RLS. D to F, Skr4 line and $\mathbf{G}$ to $\mathbf{J}, \operatorname{Tr} 66$ line. $\mathbf{D}$ and $\mathbf{G}$, Irregular cell divisions in the pericycle of the infected roots (asterisk). $\mathbf{E}$ and $\mathbf{H}$, Large round irregular cells (star) on top of abnormally divided small cells (asterisk). F and I, Morphology of moredeveloped RLS breaking through the root surface. J, Morphology of RLS showing an intermediate morphology with a regular base and abnormal cells on the top (star); vs, vascular vessels; pr, pericycle; ed, endodermis; $\mathrm{m}$, meristem. Bars $=100 \mu \mathrm{m}$. 

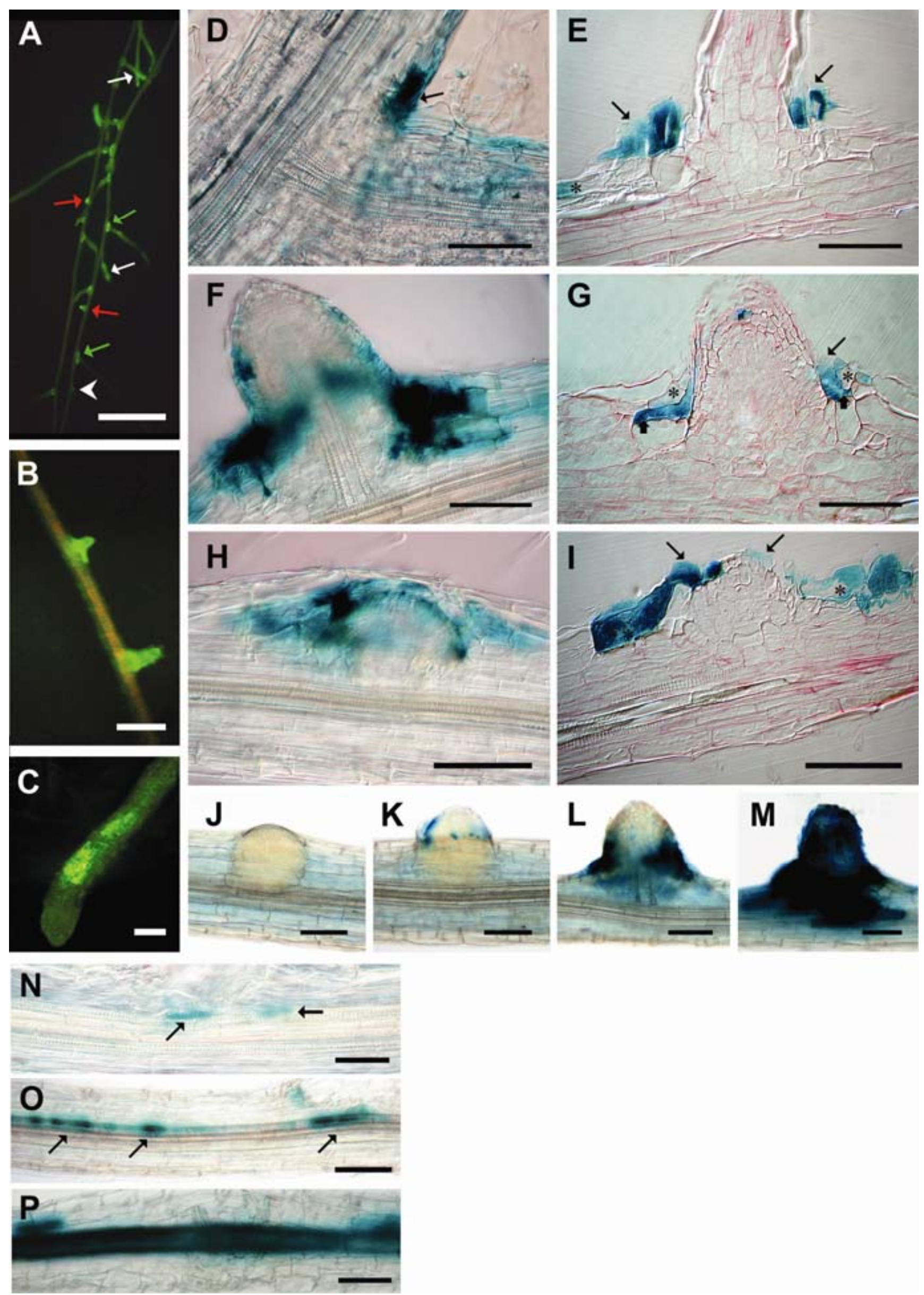
normal lateral root development, the differentiation of the different tissue layers occurs prior to the activation of the meristem (Casson and Lindsey 2003). In addition, the action of the bacterium is not confined to pericycle founder cells because intermediate structures consisting of a base resembling a normal lateral root topped by a mass of round enlarged cells also are observed. It should be noted that these intermediate structures also are devoid of a meristem, pointing to a role of the bacterial signal in interfering with the appearance or persistence of the root meristem.

\section{Importance of the RLS in the $R$. solanacearum life cycle.}

Our results show that the presence of RLS is not required for invasion of the petunia vascular system, the prerequisite for systemic infection and expression of disease symptoms. This is in accordance with observations reported in tomato that $R$. solanacearum hrp mutants still are able to invade the vascular system (Frey et al. 1994; Vasse et al. 2000).

What, then, might be the role of the RLS in petunia-R. solanacearum interactions? A clue may come from the observation that the RLS are more intensely colonized than the axils of developed lateral roots. Indeed, just-emerging lateral roots close to the root tips frequently were reported as preferential colonization sites, not only for plant pathogens but also for various epiphytic or endophytic rhizosphere bacteria that are harmless or even useful for plants (Boddey 1995; James and
Olivares 1997; Lugtenberg et al. 2001). These particular sites are proposed to act as temporary sinks for metabolites and hormones essential for lateral root initiation and development (Charlton 1996; Peterson and Peterson 1986) and to produce exudates rich in diverse metabolic compounds, such as sugars, organic acids, or vitamins (Lugtenberg et al. 2001), thereby providing an ideal nutritional environment for bacterial growth. The accumulation of RLS similarly could create numerous nutritional niches on the roots that allow an increased bacterial epiphytic multiplication, leading to greater bacterial survival and dissemination.

\section{What might be the factors involved in the induction of RLS formation?}

Both hormonal balances and nutrient availability influence root architecture. The responses of roots to these stimuli are very diverse and often involve a concomitant inhibition of primary root elongation and proliferation of lateral roots. (Casson and Lindsey 2003; Casimiro et al. 2003; Lopez-Bucio et al. 2003). R. solanacearum infection provokes an inhibition of root elongation that is observed with both the wild-type bacterium and the hrp mutants, independently from the occurrence of RLS. This indicates that the signal responsible for this inhibition is not sufficient for inducing the formation of the RLS. On the other hand, new RLS are formed continuously and we were not able to detect bacteria in the vicinity of most of these

Fig. 5. Ralstonia solanacearum infection in petunia roots. A to M, Sites of petunia root colonization by $R$. solanacearum. A, B, and C, The GMI1600 (gfp) strain was visualized by fluorescence microscopy on fresh tissue. D to M, The GMI1485 (lacZ) strain was localized by histochemical staining of $\beta$-galactosidase activity. After staining, roots were $\mathbf{D}, \mathbf{F}, \mathbf{H}$, and $\mathbf{J}$ to $\mathbf{M}$, cleared in lactic acid for at least $24 \mathrm{~h}$ or embedded in Technovit, sectioned, and stained with $\mathbf{E}$, ruthenium red or $\mathbf{G}$ and $\mathbf{I}$, safranin. Pictures D through I were taken using differential interference contrast microscopy and pictures $\mathbf{J}$ through $\mathbf{M}$ were taken using classical light microscopy. A, The upper part of a root system showing bacterial colonization of the lateral root tips (white arrows), axils of lateral roots (green arrows), and lateral structures (red arrows). The white arrowhead marks a root lateral structure (RLS) showing no signs of colonization. B, Colonization of lateral structures. C, Magnification of a colonized root tip. D, Axil colonization (arrow) of well-developed lateral roots. E, Longitudinal section of a site equivalent to the one presented in D showing bacterial colonization of the root surface (arrows) and the epidermal cells (asterisks). Intensive bacterial colonization of F, mature and $\mathbf{H}$, nascent RLS. G and I, Longitudinal sections of sites equivalent to the ones presented on $\mathrm{F}$ and $\mathrm{H}$ showing bacterial colonization on the root surface (thin arrows), the cracks in the axils (thick arrows), and epidermal cells (asterisks) at these sites. $\mathbf{J}$ to $\mathbf{M}$, Scale of intensity of bacterial colonization at RLS ranging from no colonization $(\mathrm{J})$ to intense colonization $(\mathbf{M})$. $\mathbf{N}$ to $\mathbf{P}$, Vascular invasion of petunia roots. Petunia roots were inoculated with the GMI1485 (lacZ) strain and bacteria were localized by histochemical staining of $\beta$-galactosidase activity. After staining, roots were cleared in lactic acid for at least $24 \mathrm{~h}$ and observed using differential interference contrast microscopy. N, Beginning of vascular invasion (arrows). O, More intensively colonized vascular vessels (arrows). P, Vascular vessels entirely filled with bacteria. B, D, E, G, J, K, and O = Skr4 line and A, C, F, H, I, L, M, N, and P= Tr66 line. All pictures present plants 7 days after inoculation, except $\mathrm{F}, \mathrm{H}, \mathrm{N}$, and $\mathrm{O}$, which show plants 5 days after inoculation. Scale bar: $\mathrm{A}=1 \mathrm{~cm}, \mathrm{~B}=0.5$ $\mathrm{cm}, \mathrm{C}=1 \mathrm{~mm}$, and D-P = $100 \mu \mathrm{m}$.

\section{Skr4}

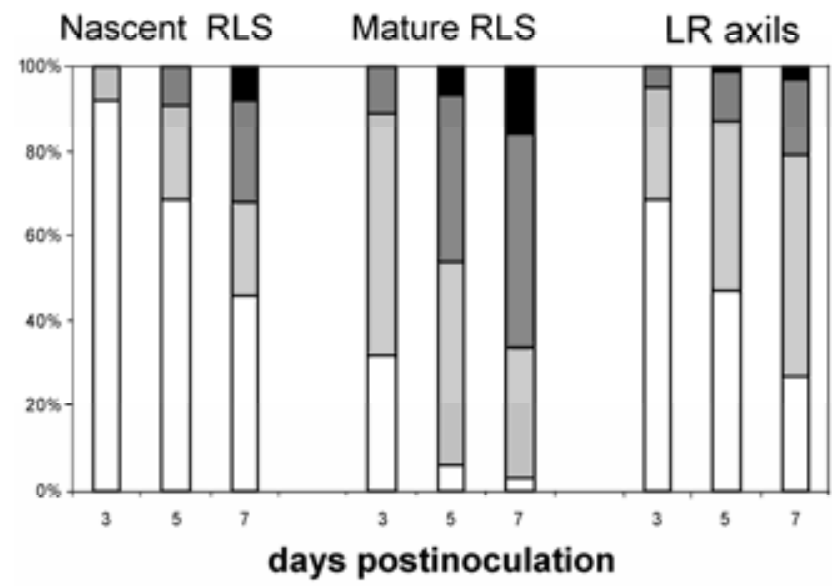

Tr66

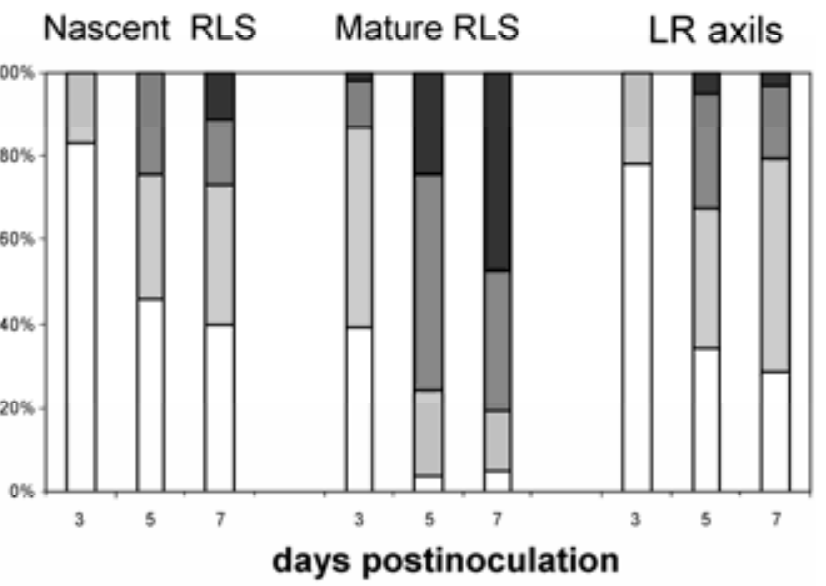

Fig. 6. Colonization efficiencies of lateral root (LR) axils and nascent and mature root lateral structures (RLS). The extent of bacterial colonization was evaluated microscopically. White bars = no colonization, light gray bars = slight colonization, dark gray bars = medium colonization, and black bars = intensive colonization. The bars show the percentage of each colonization category within the total number of sites present on the main root at each timepoint for the two petunia lines analyzed. These data were derived from three independent experiments in which 20 plants were examined. 
new bulges, suggesting that intense bacterial colonization is not required for RLS induction. This renders unlikely the involvement of nutrient availability changes caused by bacterial growth in RLS induction and points more to a long-range signalling originating from outside the sites of formation in this induction. However, we cannot exclude the possibility that only a few bacteria present at the formation sites that remained undetected might be sufficient for transmitting the bacteriainducing signal needed for programming the pericycle cells committed to produce RLS.

The induction of RLS seems to be quite common in petunia, as it was observed in all three lines we analyzed, two lines presented in this work as well as a third line, W115 (data not shown). Analysis of the effect of petunia root inoculation with various $R$. solanacearum strains showed that the bacterial signal responsible for RLS induction is produced by several but not all strains. There is no geographical or host correlation for RLS induction (Table 3); however, it should be noted that the three RLS-inducing strains all belong to biovar 3. It would be interesting to test more strains to see whether such a correlation is relevant. On the other hand, the induction of RLS appears to be specific to some plants because it was not observed in the interactions of $R$. solanacearum with tomato or Arabidopsis (data not shown).

The fact that the formation of RLS is impaired in Hrp mutants opens the exciting possibility that the bacteria-inducing signal needed for RLS induction might be a type III effector. Type III effectors of animal-pathogenic bacteria have been shown to disturb various host cellular processes, such as cytoskeleton dynamics or the host's surveillance systems (Cornelis and Van Gijsegem 2000). In Yersinia spp., Yops effectors either inhibit phagocytosis by macrophages or block the inflammatory response (Cornelis 2002). In pathogenic E. coli, the TTSS induce the attaching and effacing effect and pedestal formation that provide the sites for bacterial attachment to the host cells (Nougayrède et al. 2003). In plant diseases, the few Hrp type III effectors for which a role has been assigned were shown to either interfere with the induction of plant defence responses or induce the expansion of plant cells leading to hypertrophy (Büttner and Bonas 2003). In all of these responses, it is assumed that effects on the host are induced locally by injection of effectors into the reacting host cells. In this work, we report a phenomenon that might be a global effect involving the whole root system; to our knowledge, this would be the first example where a TTSS is reported to be involved in such a

Table 2. Vascular invasion of petunia roots ${ }^{\mathrm{z}}$

\begin{tabular}{llll}
\hline & \multicolumn{3}{c}{ Tr66 line (\%) } \\
\cline { 2 - 4 } Bacterial strain & \multicolumn{1}{c}{$\mathbf{3 ~ d p i}$} & $\mathbf{5 ~ d p i}$ & \multicolumn{1}{c}{$\mathbf{~ d p i}$} \\
\hline GMI 1485 (wild type) & $26.7 \pm 23.7$ & $65.0 \pm 13.2$ & $66.4 \pm 10.4$ \\
GMI 1541 (hrpB) & $15.0 \pm 7.1$ & $35.0 \pm 7.1$ & $35.0 \pm 7.1$ \\
\hline
\end{tabular}

${ }^{\mathrm{z}}$ Data were derived from three independent experiments including 20 plants each; dpi = days postinfection. reprogramming of an organogenesis program. The observation that RLS are efficient colonization sites points to a role of these structures in the rhizosphere-related phase of $R$. solanacearum interactions with plants. Such a role for hrp genes in the epiphytic phase of the bacterial life cycle also was proposed for other plant-pathogenic bacteria. In Pseudomonas syringae, the Hrp type III secretion system was shown to be important in enabling the bacterium to flourish in the phyllosphere (Hirano et al. 1999). In Xanthomonas spp., some members of the AvrBs3 family of type III effectors were proposed to contribute to the ecological fitness of the bacterium by increasing their release from the mesophyll to the leaf surface, leading to increased bacterial dispersal in the environment (Yang et al. 1994). This also might be supported by the fact that TTSS recently were described in nonpathogenic bacteria associated with plants as $P$. fluorescens or nodulating rhizobia (Marie et al. 2001; Preston et al. 2001). The fact that RLS induction is specific to certain plants and only some $R$. solanacearum strains also can fit with the hypothesis of a type IIImediated signal. Indeed, effects of type III effectors restricted to the interactions with certain plant species already have been reported. For example, a mutation in TTSS of the broad host range NGR234 Rhizobium has a positive, negative, or no effect on nodulation, depending of the inoculated plant (Viprey et al. 1998). Strain specificity might be explained by differences in the repertoire of type III effectors present in the different bacteria.

As Hrp mutants often are impaired in fitness and colonization proficiency, we however cannot exclude the possibility that TTSS may have only an indirect role in RLS formation, such as enhancing initial colonization of the root surface, which, in turn, enables production of another factor that stimulates RLS formation. For example, it was reported that GMI1000 possesses genes involved in plant hormone biosynthesis, such as auxin and ethylene (Salanoubat et al. 2002). Some root architecture alterations, such as inhibition of root elongation, are induced by inoculation of both the parental strain and the Hrp mutants; therefore, root colonization by the Hrp mutants is at least sufficient for interfering with root development. However, the hypothesis that signalling for the different inoculation effects might require a different level of signal and, thus, of colonization cannot be ruled out. To assess directly the role of a type III effector on RLS production, the next goal will be to determine whether, among the more than $40 \mathrm{R}$. solanacearum effector candidates disclosed by genomic analyses, we could find one responsible for this induction of new root structures.

\section{MATERIALS AND METHODS}

Plant material, plant growth conditions, and inoculation.

Petunia (Petunia hybrida) lines used in this study were Skr4 and Tr66, resistant and susceptible, respectively, to bacterial wilt (Arlat et al. 1994). For in vitro plates experiment, seed were surface sterilized in $5 \%$ (vol/vol) $\mathrm{NaOCl}$ for $3 \mathrm{~min}$ and washed five times for $5 \mathrm{~min}$ in sterile $\mathrm{H}_{2} \mathrm{O}$. Plants were germinated and grown in vitro on Gamborg's B5 medium supplemented with

Table 3. Bacterial strains used in this study

\begin{tabular}{llll}
\hline Bacterial strain & \multicolumn{1}{c}{ Description } & Origin \\
\hline GMI1000 & Wild type, race 1 biovar 3, isolated from tomato & Guyana \\
GMI1600 & GMI1000 constitutively expressing the gfp gene & $\ldots$ & Boucher et al. 1985 \\
GMI1485 & GMI1000 constitutively expressing the lacZ gene & $\ldots$ & Aldon et al. 2000 \\
GMI1541 & GMI1485 hrpB:: $\Omega$ & $\ldots$ & Arlat et al. 1992 \\
GMI1595 & GMI1000 hrcR5::apha3 & $\ldots$ & Genin et al. 1992 \\
K60 & Wild type, race 1 biovar 1, isolated from tomato & United States \\
AW1 & Wild type, race 1 biovar 1, isolated from tomato & Australia \\
GMI8084 & Wild type, race 1 biovar 3, isolated from tomato & Kelman 1954 & Denny et al. 1988 \\
GA3 & Wild type, race 1 biovar 3, isolated from eggplant & Lavie et al. 2004 Indies \\
\hline
\end{tabular}


vitamins (Duchefa, Haarlem, The Netherlands) containing 1\% agar, adjusted to $\mathrm{pH}$ 5.8. Plantlets were grown on vertical 12-by$12-\mathrm{cm}$ plates $\left(24^{\circ} \mathrm{C} ; 8 \mathrm{~h}\right.$ of dark and $16 \mathrm{~h}$ of light). Inoculations were performed on 21-day-old plants by flooding the plates with bacterial suspensions in water $\left(20 \mathrm{ml} /\right.$ plate, $\left.1 \times 10^{6} \mathrm{CFU} / \mathrm{ml}\right)$, incubating for $1 \mathrm{~h}$, and pouring out the excess inoculum. Plates subsequently were incubated at $28^{\circ} \mathrm{C}$ in $8 \mathrm{~h}$ of dark and $16 \mathrm{~h}$ of light and analyzed after 3, 5, and 7 days. Control plates were flooded with water. For soil-grown plants, inoculations were performed by watering the plants with a bacterial suspension of $10^{8} \mathrm{CFU} / \mathrm{ml}$ as described previously (Boucher et al. 1985).

\section{Bacterial strains and growth conditions.}

The $R$. solanacearum strains used in this study are described in Table 3. The GMI1600, GMI1485, and GMI1541 strains and the wild-type isolates were kindly provided by Stéphane Genin (INRA-CNRS, Castanet Tolosan, Cedex, France). For inoculation, bacterial strains were grown at $28^{\circ} \mathrm{C}$ in Gamborg's B5 medium ( $\mathrm{pH} 5.8$ ), supplemented with $20 \mathrm{mM}$ Na glutamate as a carbon source for in vitro experiments, in rich medium for soil inoculations.

\section{Assessment of the morphological changes induced by bacteria on roots.}

The influence of bacteria on the root system morphology was assessed by counting the elongated lateral roots and the bulges that appeared 7 days after inoculation on the main root between the root tip and the latest developed lateral root at the time of inoculation. The primary root elongation was assessed by measuring the difference in length between the roots 7 days after inoculation and the time of inoculation. The data were compared by three different multiple comparison statistical tests (one-way analysis of variance, Tukey's, and Dunnett's) using the Graphpad prism program. Results were scored as different when $P<0.05$ in all three tests.

\section{Histochemical assay for $\beta$-galactosidase activity.}

Whole plants were harvested from plates, prefixed in $90 \%$ acetone for $30 \mathrm{~min}$ at $4^{\circ} \mathrm{C}$ followed by three 5-min washes in Tris/NaCl buffer (100 mM Tris, $50 \mathrm{mM} \mathrm{NaCl}, \mathrm{pH}$ 7.0). Subsequently, plants were incubated for $30 \mathrm{~min}$ at $37^{\circ} \mathrm{C}$ in preincubation buffer (Tris/ $\mathrm{NaCl}$ buffer supplemented with $50 \mathrm{mM}$ $\left.\mathrm{K}_{4}\left[\mathrm{Fe}(\mathrm{CN})_{6}\right] 3 \mathrm{H}_{2} \mathrm{O}, \mathrm{pH} 7.0\right)$, stained for $3 \mathrm{~h}$ at $37^{\circ} \mathrm{C}$ in assay buffer (preincubation buffer supplemented with $50 \mathrm{mM} \mathrm{X-Gal,}$ $\mathrm{pH}$ 7.0), and washed three times for 30 min each in Tris/ $\mathrm{NaCl}$ buffer.

\section{Analysis of the morphology of the root lateral structures.}

After histochemical staining as described above, segments of roots carrying the Hrp-dependent RLS were dissected from the stained roots and fixed overnight at $4^{\circ} \mathrm{C}$ in a solution of $2.5 \%$ glutaraldehyde in Tris/ $\mathrm{NaCl}$ buffer $(\mathrm{pH} 7.0)$. After fixation, roots were washed in the same buffer, dehydrated in an ethanol series, and progressively embedded in Technovit 7100 (Heraeus Kulzer, Wehrheim, Germany) for longitudinal sections (Beeckman and Viane 1999) according to the manufacturer's instructions. Sections ( $5 \mu \mathrm{m})$ were cut using a Minot-Mikrotom 1212 (Leitz, Wetzlar, Germany) and disposable Superlab Knives (Adamas Instrumenten, Leersum, The Netherlands) and were stained for $20 \mathrm{~min}$ in fresh $0.05 \%$ aqueous solution of ruthenium red or for $1 \mathrm{~min}$ in $0.1 \%$ safranin. The sections were analyzed and photographed using differential interference contrast microscopy (DMLB; Leica, Ryswyk, The Netherlands).

\section{Analysis of root colonization.}

Plants grown on plates and inoculated as described above with $R$. solanacearum wild-type GFP strain were observed di- rectly on the agar surface using a fluorescent stereomicroscope (MZ FLIII; Leica). For more detailed analysis, histochemical staining of roots was performed as described above on plants inoculated with $R$. solanacearum strains carrying the $l a c Z$ reporter gene. Following staining, the whole root systems were detached from plants and cleared in $90 \%$ lactic acid for at least $24 \mathrm{~h}$ before analysis. Roots were evaluated and photographed using light microscopy (Leica) or DMLB (Leica). The extent of bacterial colonization was estimated microscopically by scoring the size of the colonized area and the intensity of the blue precipitate on a scale of 0 (no colonization) to 3 (intensive colonization) (Fig. 5J to M). All Hrp-dependent lateral structures present on the main root and up to five developed lateral root axils or plants beginning from the root tip were analyzed.

\section{Assessment of the vascular invasion of the root.}

Plants inoculated with lacZ-expressing bacteria were stained histochemically with X-gal and cleared in lactic acid as described above. The plants were analyzed using light microscopy (Leica). The roots were scored as positive when a blue Xgal staining was observed in the vascular vessels of the main root.

\section{ACKNOWLEDGMENTS}

L. Zolobowska was financially supported by an EC Marie Curie grant, HPMF-CT-1999-00046. We wish to thank T. Beeckman and M. Holsters for fruitful discussions; M.-a. Barny, C. Roux, and Y. Kraepiel for critical reading of the manuscript; S. M. Witiak for English revision; R. De Rycke for help with microscopic work; K. Spruyt for the whole-plant pictures; and $\mathrm{S}$. Genin for providing the $R$. solanacearum strains.

\section{LITERATURE CITED}

Abramovitch, R. B., and Martin, G. B. 2004. Strategies used by bacterial pathogens to suppress plant defenses. Curr. Opin. Plant Biol. 7:356364.

Abramovitch, R. B., Kim, Y. J., Chen, S. R., Dickman, M. B., and Martin, G. B. 2003. Pseudomonas type III effector AvrPtoB induces plant disease susceptibility by inhibition of host programmed cell death. EMBO (Eur. Mol. Biol. Organ.) J. 22:60-69.

Aldon, D., Brito, B., Boucher, C., and Genin, S. 2000. A bacterial sensor of plant cell contact controls the transcriptional induction of Ralstonia solanacearum pathogenicity genes. EMBO (Eur. Mol. Biol. Organ.) J. 19:2304-2414.

Arlat, M., Gough, C. L., Zischek, C., Barberis P. A., and Boucher, C. A. 1992. Transcriptional organization and expression of the large $h r p$ gene cluster of Pseudomonas solanacearum. Mol. Plant-Microbe Interact. 5:187-193.

Arlat, M., Van Gijsegem, F., Huet, J. C., Pernollet, J. C., and Boucher, C. A. 1994. PopA1, a protein which induces a hypersensitivity-like response on specific Petunia genotypes, is secreted via the Hrp pathway of Pseudomonas solanacearum. EMBO (Eur. Mol. Biol. Organ.) J. 13:543553.

Beeckman, T., and Viane, R. 1999. Embedding thin plant specimens for oriented sectioning. Biotech. Histochem. 75:23-26.

Boddey, R. M. 1995. Biological nitrogen fixation in sugar cane: a key to energetically viable biofuel production. Crit. Rev. Plant Sci. 14:263279.

Boucher, C. A., Barberis, P. A., Trigalet, A. P., and Demery, D. A. 1985. Transposon mutagenesis of Pseudomonas solanacearum: Isolation of Tn5-induced avirulent mutants. J. Gen. Microbiol. 131:2449-2457.

Büttner, D., and Bonas, U. 2003. Common infection strategies of plant and animal pathogenic bacteria. Curr. Opin. Plant Biol. 6:312-319.

Casimiro, I., Beeckman, T., Graham, N., Bhalerao, R., Zhang, H., Casero, P., Sandberg, G., and Bennett, M. J. 2003. Dissecting Arabidopsis lateral root development. Trends Plant Sci. 8:165-171.

Casson, S. A., and Lindsey, K. 2003. Genes and signalling in root development. New Phytol. 158:11-38.

Charlton, W. A. 1996. Lateral root initiation. Pages 149-173 in: Plant Roots: The Hidden Half. Y. Waisel, A. Eshel, and U. Kafkafi, eds. Marcel Dekker, Inc., New York.

Collmer, A., Lindeberg, M., Petnicki-Ocwieja, T., Schneider, D. J., and Alfano, J. R. 2002. Genomic mining of type III secretion system effec- 
tors in Pseudomonas syringae yields new picks for all TTSS prospectors. Trends Microbiol. 10:462-469.

Cornelis, G. R. 2002. Yersinia type III secretion: send in the effectors. J. Cell Biol. 158:401-408.

Cornelis, G. R., and Van Gijsegem, F. 2000. Assembly and function of type III secretory systems. Annu. Rev. Microbiol. 54:735-774.

Cunnac, S., Occhialini, A., Barberis, P., Boucher, C., and Genin, S. 2004 Inventory and functional analysis of the large Hrp regulon in Ralstonia solanacearum: identification of novel effector proteins translocated to plant host cells through the type III secretion system. Mol. Microbiol. 53:115-128.

Denny, T. P., Makini, F. W., and Brumbley, S. M. 1988. Characterization of Pseudomonas solanacearum Tn5 mutants deficient in extracellular polysaccharide. Mol. Plant-Microbe Interact. 1:215-223.

Deslandes, L., Olivier, J., Peeters, N., Feng, D. X., Khounlotham, M., Boucher, C., Somssich, L., Genin, S., and Marco, Y., 2003. Physical interaction between RRS1-R, a protein conferring resistance to bacterial wilt, and PopP2, a type III effector targeted to the plant nucleus. Proc. Natl. Acad. Sci. U.S.A. 100:8024-8029.

Duan, Y. P., Castaneda, A., Zhao, G., Erdos, G., and Gabriel, D. W. 1999. Expression of a single, host-specific, bacterial pathogenicity gene in plant cells elicits division, enlargement, and cell death. Mol. PlantMicrobe Interact. 12:556-560.

Frey, P., Prior, P., Marie, C., Kotoujansky, A., Trigalet-Demery, D., and Trigalet, A. 1994. Hrp ${ }^{-}$mutants of Pseudomonas solanacearum as potential biocontrol agents of tomato bacterial wilt. Appl. Environ. Microbiol. 60:3175-3181.

Genin, S., Gough, C. L., Zischek, C., and Boucher, C. 1992. Evidence that the $h r p B$ gene encodes a positive regulator of pathogenicity genes from Pseudomonas solanacearum. Mol. Microbiol. 6:3065-3076.

Guéneron, M., Timmers, A. C. J., Boucher, C., and Arlat, M. 2000. Two novel proteins, PopB, which has functional nuclear localization signals, and $\mathrm{PopC}$, which has a large leucine-rich repeat domain, are secreted through the Hrp-secretion apparatus of Ralstonia solanacearum. Mol. Microbiol. 36:261-277.

Hauck, P., Thilmony, R., and He, S. Y. 2003. A Pseudomonas syringae type III effector suppresses cell wall-based extracellular defense in susceptible Arabidopsis plants. Proc. Natl. Acad. Sci. U.S.A. 100:8577-8582.

Hayward, H. C. 1991. Biology and epidemiology of bacterial wilt caused by Pseudomonas solanacearum. Annu. Rev. Phytopathol. 29:65-87.

Hirano, S. S., Charkowski, A. O., Collmer, A., Willis, D. K., and Upper, C. D. 1999. Role of the Hrp type III protein secretion system in growth of Pseudomonas syringae pv. syringae B728a on host plants in the field. Proc. Natl. Acad. Sci. U.S.A. 96:9851-9856.

James, E. K., and Olivares, F. L. 1997. Infection and colonization of sugar cane and other graminaceous plants by endophytic diazotrophs. Crit. Rev. Plant Sci. 17:77-119.

Kelman, A. 1954. The relationship of pathogenicity of Pseudomonas solanacearum to colony appearance in a tetrazolium medium. Phytopathology 44:693-695.

Keshavarzi, M., Soylu, S., Brown, I., Bonas, U., Nicole, M., Rossiter, J., and Mansfield, J. 2004. Basal defenses induced in pepper by lipopolysaccharides are suppressed by Xanthomonas campestris pv. vesicatoria. Mol. Plant-Microbe Interact. 17:805-815.

Lavie, M., Shillington, E., Eguiluz, C., Grimsley, N., and Boucher, C. 2002. PopP1, a new member of the YopJ/AvrRxv family of type III effector proteins, acts as a host-specificity factor and modulates aggressiveness of Ralstonia solanacearum. Mol. Plant-Microbe Interact. 15:1058-1068.

Lavie, M., Seunes, B., Prior, P., and Boucher, C. 2004. Distribution and sequence analysis of a family of type III-dependent effectors correlate with the phylogeny of Ralstonia solanacearum strains. Mol. PlantMicrobe Interact 17:931-940.

Leach, J. E., and White, F. F 1996. Bacterial avirulence genes. Annu. Rev. Phytopathol. 34:153-179.

Lopez-Bucio, J., Cruz-Ramirez, A., and Herrera-Estrella, L. 2003. The role of nutrient availability in regulating root architecture. Curr. Opin. Plant Biol. 6:280-287.

Lugtenberg, B. J. J., Dekkers, L., and Bloemberg, G. V. 2001. Molecular determination of rhizosphere colonization by Pseudomonas. Annu. Rev. Phytopathol. 39:461-490.

Mackey, D., Belkhadir, Y., Alonso, J. M., Ecker, J. R., and Dangl, J. L. 2003. Arabidopsis RIN4 is a target of the type III virulence effector AvrRpt2 and modulates RPS2-mediated resistance. Cell 112:379-389.

Malamy, J. E., and Benfey, P. N. 1997. Organization and cell differentiation in lateral roots of Arabidopsis thaliana. Development 124:33-44.

Marie, C., Broughton, W. J., and Deakin, W. J. 2001. Rhizobium type III secretion systems: legume charmers or alarmers? Curr. Opin. Plant Biol. 4:336-342.

Marois, E., Van den Ackerveken, G., and Bonas, U. 2002. The Xanthomonas type III effector protein AvrBs3 modulates plant gene expression and induces cell hypertrophy in the susceptible host. Mol. PlantMicrobe Interact. 15:637-646.

Mudgett M. B. 2005. New insights to the function of phytopathogenic bacterial type III effectors in plants. Annu. Rev. Plant Biol. 56:509-531.

Nougayrède, J.-P., Fernandes, P. J., and Donnenberg, M. S. 2003. Adhesion of enteropathogenic Escherichia coli to host cells. Cell. Microbiol. 5:359-372.

Peterson, R. L., and Peterson, C. A. 1986. Ontogeny and anatomy of lateral roots. Pages 1-31 in: New Root Formation in Plants and Cuttings. M. B. Jackson, ed. Martinus Nijhoff, Hingham, MA, U.S.A.

Preston, G. M., Bertrand, N., and Rainey, P. B. 2001. Type III secretion in plant growth-promoting Pseudomonas fluorescens SBW25. Mol. Microbiol. 41:999-1014.

Rathjen, J. P., and Moffett, P. 2003. Early signal transduction events in specific plant disease resistance. Curr. Opin. Plant Biol. 6:300-306.

Salanoubat, M., Genin, S., Artiguenave, F., Gouzy, J., Mangenot, S., Arlat, M., Billault, A., Brottier, P., Camus, J. C., Cattolico, L., Chandler, M., Choisne, N. Claudel-Renard, C., Cunnac, S. Demange, N., Gaspin, C., Lavie, M., Moisan, A., Robert, C., Saurin, W., Schiex, T., Siguier, P., Thebault, P., Whalen, M., Wincker, P., Levy, M., Weissenbach, J., and Boucher, C. A. 2002. Genome sequence of the plant pathogen Ralstonia solanacearum. Nature 415:497-502.

Van Gijsegem, F., Vasse, J., De Rycke, R., Castello, P., and Boucher, C. 2002. Genetic dissection of the Ralstonia solanacearum hrp gene cluster reveals that the HrpV and HrpX proteins are required for Hrp pilus assembly. Mol. Microbiol. 44:935-946.

Vasse, J., Frey, P., and Trigalet, A. 1995. Microscopic studies of intercellular infection and protoxylem invasion of tomato roots by Pseudomonas solanacearum. Mol. Plant-Microbe Interact. 8:241-251.

Vasse, J., Genin, S., Frey, P., Boucher, C., and Brito, B. 2000. The hrpB and $h r p G$ regulatory genes of Ralstonia solanacearum are required for different stages of the tomato root infection process. Mol. PlantMicrobe Interact. 13:259-267.

Viprey, V. Del Greco, A., Golinowski, W., Broughton, W. J., and Perret, X. 1998. Symbiotic implications of type III protein secretion machinery in Rhizobium Mol. Microbiol. 28:1381-1389.

Yang, Y., De Feyter, R., and Gabriel, D. W. 1994. Host-specific symptoms and increased release of Xanthomonas citri pv. malvacearum from leaves are determined by the 102-bp tandem repeats of pthA and avrb6, respectively. Mol. Plant-Microbe Interact. 7:345-355. 